\title{
ACANTHACEAE DO PARQUE ESTADUAL DE IBITIPOCA, MINAS GERAIS, BRASIL
}

\author{
ISABEL GOMIDE MARTINELLI \& RENATO MELLO-SILVA
}

\author{
Departamento de Botânica, Instituto de Biociências, Universidade de São Paulo. \\ Rua do Matão, 277, edifício Sobre-as-Ondas, 05508-090 - São Paulo, SP, Brasil. \\ E-mail: mellosil@usp.br
}

\begin{abstract}
Acanthaceae from the Ibitipoca State Park, Minas Gerais, Brazil). A survey of Acanthaceae species from the Ibitipoca State Park is presented. The park is located in the Mantiqueira mountain range. The family is represented in the Park by three genera and six species, Mendoncia mollis, Ruellia geminiflora, Justicia monticola, J. beyrichii, J. dasyclados and J. sebastianopolitana. Key for the species, descriptions and illustrations are provided.
\end{abstract}

Key words: Acanthaceae, Lamiales, angiosperms, flora, Ibitipoca.

Resumo - (Acanthaceae do Parque Estadual de Ibitipoca, Minas Gerais, Brasil). O estudo da família Acanthaceae é parte do levantamento da flora do Parque Estadual de Ibitipoca, situado em Minas Gerais, nos municípios de Santa Rita de Ibitipoca e Lima Duarte, a $21^{\circ} 40^{\prime}-21^{\circ} 44^{\prime} \mathrm{S}$ e $43^{\circ} 52^{\prime}-43^{\circ} 55^{\prime} \mathrm{W}$. A família está representada na área por seis espécies, Mendoncia mollis, Ruellia geminiflora, Justicia monticola, J. beyrichii, J. dasyclados e J. sebastianopolitana. São apresentadas chaves para gêneros e espécies, além de descrições, ilustrações, e comentários sobre as espécies.

Palavras-chave: Acanthaceae, Lamiales, angiospermas, flora, Ibitipoca.

Introdução

Acanthaceae abrange entre 201 e 212 gêneros e 3175 a 3510 espécies (Mabberley 2008, Scotland \& Vollesen 2000), de distribuição pantropical, com poucos representantes nas regiões temperadas. O Brasil é um dos principais centros de diversidade da família e comporta 40 gêneros e 450 espécies (Profice et al. 2014). A família tem muitas espécies de alto valor ornamental por suas brácteas e flores chamativas e, em alguns casos, folhas variegadas (Barroso 1978). Espécies de 36 gêneros diferentes são cultivadas para este fim. A família não se destaca por sua importância econômica, mas algumas espécies são utilizadas para branquear ou corar tecidos e outras têm uso medicinal (Wasshausen \& Wood 2004). Na África tropical ocidental há registro de 103 espécies úteis (Burkill 1985).

Um tratamento, de Nees von Esenbeck (1847), abrange a família Acanthaceae no Brasil, mas poucos são os trabalhos recentes que tratam de espécies brasileiras. Em Minas Gerais, há três trabalhos florísticos sobre as Acanthaceae, os de Kameyama (1995, 2003) e o de Braz et al. (2002).

Como forma de ampliar o conhecimento sobre a diversidade vegetal da região de Minas Gerais, foram realizados estudos sobre a flora do Parque Estadual de Ibitipoca (Andrade \& Sousa 1995; Borges \& Forzza 2008; Carvalho et al. 2000; Ferreira \& Magalhães 1977; Forzza et al. 1994, 2013; Medeiros \& Guimarães 2007; Menini Neto \& Forzza 2007; Milwardde-Azevedo 2007; Monguilhott \& Mello-Silva 2009;
Rodela 1998; Salimena-Pires 1997), que foi considerada área prioritária para a conservação da flora do estado (Drummond et al. 2005). O objetivo deste trabalho é contribuir para a publicação de informações sobre a flora local e assim, fornecer dados importantes para ações de conservação no parque.

\section{Material e Métodos}

O Parque Estadual do Ibitipoca está localizado entre os municípios de Lima Duarte e Santa Rita do lbitipoca, no sudeste de Minas Gerais, entre as coordenadas 2140' - 214' S e 4352' - 435' W, fazendo parte da região da Zona da Mata mineira e da Serra da Mantiqueira. São 1923,5 hectares que, desde 1965, estão sob responsabilidade do Instituto Estadual de Florestas. O parque é formado por um mosaico de vegetações, entre elas campo rupestre, cerrado, mata ciliar, ombrófila e alto-montana (Rodela \& Tarifa 2002, Menini Neto 2007, Forzza et al. 2013).

Foram feitas análises morfológicas do material herborizado coletado no Parque Estadual do Ibitipoca e depositado nos herbários BHCB, CESJ, RB e SPF (siglas segundo Thiers 2010). As descrições de morfologia seguem Hickey (1973) para as folhas, Theobald et al. (1979), para tricomas e Bell (1991) para inflorescências. A literatura específica da família é a de Nees (1847). Coletas de novos espécimes e observação de populações foram realizadas durante estudos de campo em janeiro e dezembro de 2010, em todos os tipos vegetacionais do parque. A 
identificação das espécies foi feita com auxílio da literatura e, quando necessária, consulta a fotografias dos tipos nomenclaturais depositados nos herbários $B$, F, GZU, K e P. Foram elaboradas descrições das espécies e suas variações populacionais e chaves de identificação. llustrações foram feitas com uso de estereomicroscópio Olympus SZH10 com câmaraclara acoplada.

\section{Resultados e Discussão}

Há no Parque Estadual do Ibitipoca seis espécies de três gêneros de Acanthaceae, Justicia beyrichii, J. dasyclados, J. monticola, J. sebastianopolitana, Mendoncia mollis e Ruellia geminiflora.

Chave de identificação das espécies de Acanthaceae

1. Flores solitárias ou geminadas, corola tubulosa, estames 4 , didínamos

2. Liana, ramos densamente amarelo-pubescentes, brácteas 2,0-2,2 x 1,3-1,5 cm, corola branca com listras vináceas no interior do tubo, fruto drupa

2'. Erva, ramos densamente branco-pubescentes, brácteas ausentes, corola roxa a lilás, fruto cápsula

1'. Flores em inflorescências com mais de duas flores, corola bilabiada, estames 2

3. Subarbusto escandente, ramos glabrescentes a densamente pubescentes, lâminas foliares 3,5-5,0 cm compr.

3'. Ervas eretas, ramos glabros a glabrescenteces, lâminas foliares 5,9-16,5 cm compr

4. Ramo fistuloso. Inflorescência 2,3 a $4,5 \mathrm{~cm}$ compr., flores densamente dispostas, brácteas unguiculadas e bractéolas lineares, corola totalmente branca

4'. Ramo não fistuloso. Inflorescência 4 a $13 \mathrm{~cm}$ compr., flores esparsamente dispostas, brácteas e bractéolas triangulares ou lanceoladas, corola branca com manchas roxas ou vermelha

5. Brácteas e bractéolas triangulares, cálice 4-partido, corola branca com manchas roxas 5'. Brácteas e bractéolas lanceoladas, cálice 5-partido, corola vermelha 1.1 Mendoncia mollis 2.1 Ruellia geminiflora 3.1 Justicia monticola 3.2 Justicia beyrichil

1.1. Mendoncia mollis Lindau, Bot. Jahrb. Syst. 25(60): 44. 1898.

Liana. Ramos cilíndricos, fistulosos, densamente amarelo-pubescentes, entrenó 11-16 cm compr. Folhas membranáceas, pecíolo $0,7-2,3 \mathrm{~cm}$ compr.; lâmina 7,6-11,5 cm compr., 2,8-5,5 cm larg., elíptica, ápice agudo, acuminado, base obtusa, margem inteira, face adaxial amarelo-pubescente, nervura primária proeminente, face abaxial pubescente, nervuras primária e secundárias proeminentes. Flores solitárias ou geminadas, axilares, pedicelo ca. 1,3 cm compr., bráctéas elípticas a ovadas, ápice mucronado, base obtusa, 2,0-2,2 cm compr., 1,3-1,5 cm larg., face externa densamente amarelo-pubescente, face interna com glândulas sésseis, cálice cupuliforme inteiro, ca. 1,2 mm compr., corola branca com listras vináceas no interior do tubo, 3,1 cm compr., 2 lobos superiores, 3 inferiores, ca. 0,9 $\mathrm{cm}$ compr., superiores ca. $1 \mathrm{~cm}$ larg., inferiores ca. 0,8 cm larg.; estames 4, insertos, didínamos, adnados ao tubo da corola, anteras bitecas, tecas da antera presas em alturas diferentes do conectivo; ovário ovóide, estigma bilobado em forma de ferradura, disco nectarífero cobrindo dois quintos proximais do ovário. Cápsulas ovóides, 1,5 cm compr., 1,0 cm larg., imaturas verdes, maduras vináceas, indumento denso, amarelo, glabrescente. Sementes não observadas.

Material examinado: MINAS GERAIS: Lima Duarte, Parque Estadual de Ibitipoca, Mata Grande, 21.IX.2006 (fl, fr), R.C. Forzza et al. 4286 (RB); Mata Grande, 10.III.2004 (fr),
R.C. Forzza et al. 3144 (RB); Gruta do Monjolinho, beira da mata ciliar, 16.XII.2010 (fl), I.G. Martinelli et al. 4 (SPF).

Mendoncia mollis ocorre, no Brasil, em Minas Gerais e Goiás (Profice 1988, Profice et al. 2014). No Parque de Ibitipoca é encontrada em regiões de mata ciliar ou matas próximas a grutas.

2.1. Ruellia geminiflora Kunth in Humboldt, Bonpland \& Kunth, Nov. gen. sp. 2: 240. 1818.

Ervas eretas, até $10 \mathrm{~cm}$ compr. Ramos cilíndricos, densamente pubescentes. Folhas membranáceas, subsésseis; lâmina 1,5-3,5 cm compr., 0,6-1,4 cm larg., elíptica a obovada, ápice agudo a obtuso, base cuneada, margem inteira, densamente pubescente, tricomas glandulares sésseis, nervuras pouco visíveis. Flores solitárias ou geminadas, terminais ou axilares, subsésseis; brácteas e bractéolas ausentes; cálice 5-partido, 1,0$1,5 \mathrm{~cm}$ compr., sépalas unidas no quarto proximal, lineares, densamente pubescentes; corola roxa a lilás, 3-4 cm compr., lobos orbiculares 1,0-1,5 cm diâm., garganta 1,5-2,0 cm compr., tubo basal ca. $1 \mathrm{~cm}$ compr., glabrescentes; estames 4, didínamos, insertos, adnados $1,5 \mathrm{~cm}$ abaixo do ápice do tubo da corola, anteras bitecas, paralelas; ovário pubescente, estilete esparsamente pubescente. Cápsulas ca. $1 \mathrm{~cm}$ compr., ca. 0,7 cm larg. Sementes não observadas.

Material examinado: MINAS GERAIS: Lima Duarte, Conceição do Ibitipoca, entre 1.100 e 1.200 m, em formação 
campestre, 26.IX.1970 (fl), D. Sucre et al. 7111 (RB); Serra de Ibitipoca, próximo à gruta Martimiano, mata de candeia, 11.XI.1987 (fl), Sousa \& Feio s.n. (BHCB 16675).

Material adicional: MINAS GERAIS: Datas, Morro do Coco, Rodovia Datas-Gouveia, $3 \mathrm{~km}$ noroeste de Datas, afloramentos rochosos, campo limpo, mata ciliar e capão, 26.IX.2006 (fl, fr), Lovo et al. 181 (SPF); Lima Duarte, Conceição do Ibitipoca, estrada para Santana do Garambéu, 17.XI.2001 (fl), Pires \& Nobre 976 (CESJ); São João del Rei, na capoeira e no campo, X.1969 (fl), Krieger 7208 (CESJ).

Ruellia geminiflora é uma espécie amplamente distribuída, ocorrendo na América Central, e América do Sul (Ezcurra 1993). A espécie apresenta variação morfológica muito grande, em parte devido à sua capacidade de regeneração após queimadas naturais (Kameyama 1995). No Parque de Ibitipoca, ocorre nas regiões conhecidas como matas de candeia e em campos.

\section{Justicia L.}

Ervas ou subarbustos, eretos ou escandentes. Ramos glabros a pubescentes, cistólitos presentes. Folhas opostas, sésseis ou pecioladas. Inflorescências em espigas simples ou compostas, terminais ou axilares, com subunidades dicasiais ou espiciformes, ocasionalmente reduzidas a um aglomerado de flores, raramente uma flor solitária. Flores subtendidas por uma bráctea e duas bractéolas; cálice 4-5-partido, sépalas unidas somente na base; corola com tubo estreito, curto ou alongado, bilabiada, lábio superior estreito, bífido ou levemente bilobado, raramente inteiro, quase sempre rugulado, lábio inferior mais largo, trilobado, com palato manchado e venação peninérvia; estames 2, inseridos no tubo da corola, anteras 2-tecas, exclusas, uma ou ambas as tecas apendiculadas na base ou não, tecas sobrepostas a quase paralelas ao conectivo, estaminódio ausente; disco nectarífero inteiro ou sinuado-lobado; óvulos 2 por lóculo, estigma bilobado apical ou lateralmente, excluso. Cápsula com a porção proximal lateralmente comprimida e a porção distal cilíndrica, ovoide ou subesférica, com os septos com retináculos. Sementes 4 ou menos por aborto.

3.1. Justicia beyrichii (Nees) Lindau, Nat. Pflanzenfam. 4(3b): 350. 1895.

Fig. 1C, D.

Ervas eretas. Ramos cilíndricos, tetrasulcados porção logo acima dos nós intumescida, tricomas dispostos em duas fileiras longitudinais opostas, cruzadas em relação ao eixo das folhas. Folhas sésseis a subsésseis; lâmina 6,5-16,5 cm compr., 1-2 cm larg., membranácea, estreitamente elíptica a lanceolada, ápice atenuado, base agudo-atenuada, margem inteira, nervuras central e secundárias proeminentes em ambas as faces, face adaxial brilhante, glabra, face abaxial esparsamente pubescente. Flores em espiga terminal; raque 2,3-4,5 cm compr.; brácteas imbricadas, unguiculadas, 10-12 $\mathrm{mm}$ compr., 6-7 mm larg., pubescentes, ápice obtuso, base cuneada; bractéolas lineares, ca. 9,5 mm compr., pubescentes; cálice 5-partido, verde, glabrescente, lacínias unidas próximo à base, triangulares, ca. 7,5 $\mathrm{mm}$ compr., corola branca, 1,5-2,0 cm compr., tubo ca. $1 \mathrm{~cm}$, lábios ca. $6 \mathrm{~mm}$ compr., o dorsal ereto, bidentado, o ventral trilobado, lobo central ca. $3 \mathrm{~mm}$ compr., os laterais ca. $1,7 \mathrm{~mm}$ compr.; estames inseridos 0,5 $\mathrm{mm}$ abaixo do ápice do tubo, filetes ca. 1 $\mathrm{cm}$ compr., tecas subparalelas, sobrepostas, apendiculadas, apêndice superior ca. 0,1 mm, o inferior ca. 0,4 $\mathrm{mm}$; disco nectarífero recobrindo o terço proximal do ovário. Cápsulas ca. $1 \mathrm{~cm}$ compr., $3,5 \mathrm{~mm}$ larg., estipitadas, apiculadas, às vezes com estilete persistente, glabras; retináculo ca. $1,5 \mathrm{~mm}$ compr.; sementes ca. $1,5 \mathrm{~mm}$ diâm., orbiculares, côncavo-convexas, glabras, tuberculadas.

Material examinado: MINAS GERAIS: Lima Duarte, Parque Estadual de Ibitipoca, Mata Grande, iniciando descida, 16.III.2005 (fl, fr), Medeiros et al. 410 (RB); Mata Grande, ao lado da trilha para o Pico do Pião, cerca de 1000 $\mathrm{m}$ após a Prainha, 27.I.2010 (fl, fr), Martinelli et al. 3 (SPF); mata pluvial montana, 28.IV.1988 (fl. fr), Andrade s.n. (BHCB 15999); Mata Grande, mata de galeria em altitude, 18.IV.1987 (fl), Sousa s.n. (BHCB 13895); Mata Grande, 10.III.2004 (fl), Forzza et al. 3154 (CEPEC, CESJ, MBM, NY, $\mathrm{RB}, \mathrm{SP})$.

Material adicional: SÃO PAULO: Jundiaí, Serra do Japi, 18.IV.1995 (fl), Kiyama et al. 78 (SPF); Serra do Japi, 21.I.1976 (fl), Leitão Filho et al. 1611 (RB); RIO DE JANEIRO: Magé, Fazenda Mandioca, XI-XII.1822 (fl), Riedel s.n. (GZU 250084); Serra da Estrela, elev. 550 m, 16.X.1977 (fl), Maas \& Carauta 3246 (RB); Mangaratiba, Reserva Ecológica de Rio das Pedras, trilha do Cambucá, elev. 250300 m, 26.IX.2001 (fl, fr), Profice 115 (RB); limite de municípios Niterói-Maricá, pico Alto Moirão, 16.XI.1983 (fl, fr), Farney et al. 365 (RB); Teresópolis, Cascata dos Amores, elev. 950 m, 12.V.1949 (fl, fr), Barbosa Pereira 134 (RB).

Justicia beyrichii ocorre em Minas Gerais, São Paulo e Rio de Janeiro (Profice et al. 2014). Como descrita por Nees (1847), J. beyrichii teria a porção proximal da lâmina com margem ondulada, conectivo da antera longo e anteras com uma teca paralela e outra em ângulo agudo em relação ao filete, sem apêndice. As populações de J. beyrichii de Ibitipoca têm, no entanto, a lâmina foliar com margem plana, anteras com conectivo curto e tecas subparalelas, sobrepostas, apendiculadas. Além disso, diferentemente da maioria das populações de $J$. beyrichii, as de Ibitipoca têm as brácteas e bractéolas maiores, a lâmina foliar estreitamente elíptica a lanceolada, não oblonga a obovada, e a porção distal das brácteas e bractéolas com tricomas glandulares, não ciliada. Variações muito semelhantes às de Ibitipoca ocorrem em populações distantes, como naquelas da Serra do Japi, no Estado de São Paulo, ou mais próximas, como nas de Magé e Mangaratiba, no Estado do Rio de Janeiro. Estas diferenças morfológicas, no entanto, sofrem variações gradativas e podem não ser suficientes para justificar 
classificações diferentes dessas populações. No Parque de Ibitipoca, há populações abundantes de J. beyrichii na Mata Grande.

3.2. Justicia dasyclados (Nees) Lindau, Nat. Pflanzenfam. 4(3b): 350. 1895.

Fig. 1A, B.

Ervas eretas. Ramos cilíndricos, subglabrescentes, base do entrenó intumescido, arroxeado. Folhas membranáceas; pecíolo 3-10 mm compr.; lâmina 6,0-14,5 cm compr., 1-3 cm larg., elíptica, oblonga ou ovada, ápice atenuado, base aguda a cuneada, margem inteira, subglabrescente, face adaxial brilhante, face abaxial com base arroxeada, nervuras primária e secundárias proeminentes em ambas as faces. Flores em espiga terminal ou axilar; raque 4-13 cm compr.; brácteas triangulares, ca. 4,5 mm compr., glabras; bractéolas triangulares, $4 \mathrm{~mm}$ compr., glabras; cálice 4-partido, verde, sépalas unidas somente na base, ca. $9 \mathrm{~mm}$ compr.; corola branca, 2,0-2,5 cm compr., lábios ca. 5 $\mathrm{mm}$ compr., o dorsal ereto, bidentado, o ventral trilobado, ca. $4 \mathrm{~mm}$ compr., com manchas roxas, o central mais largo; estames inseridos pouco abaixo do ápice do tubo, filetes ca. 9,5 mm compr., curvados no ápice, tecas sem apêndice, a inferior ligeiramente menor; disco nectarífero fendido na parte anterior e posterior. Frutos e sementes não observados.

Material examinado: MINAS GERAIS: Lima Duarte, Parque Estadual de Ibitipoca, Gruta dos Viajantes e córrego Monjolinho, margem direita da mata ciliar próxima à gruta, 25.I.2010 (fl), Martinelli et al. 2 (SPF); Gruta dos Viajantes, local sombreado, na mata, 23.II.1992 (fl), Eiterer \& Freitas 71 (CESJ); Pico do Pião, na mata, elev. 1580-1600 m, 13.V.1970 (fl), Sucre \& Krieger 6760 (RB).

Material adicional: SÃO PAULO: Nazaré Paulista, estrada de terra para Piracaia, 10.IV.1995 (fl, fr), Tamashiro et al. 757 (SPF).

Justicia dasyclados ocorre em São Paulo e Minas Gerais (Profice et al. 2010). É pouco comum no Parque de Ibitipoca, embora haja uma grande população na região da mata ciliar da Gruta dos Viajantes, que se estende por todo o córrego Monjolinho. Possui cistólitos abundantes e visíveis a olho nu por todas as partes vegetativas.

\subsection{Justicia monticola (Nees) Profice,} Rodriguésia 61(Supl.): 587. 2010.

Fig. 1E

Subarbustos escandentes, até $3 \mathrm{~m}$ compr.
Ramos cilíndricos, pubescentes.
membranáceas a cartáceas; pecíolo $3-10 \mathrm{~mm}$ compr.;
lâmina 3,5-5,0 cm compr., 1,6-2,8 cm larg., elíptica a
ovada, ápice agudo a atenuado, base assimétrica,
obtuso-arredondada a aguda, margem inteira a
levemente crenada, face adaxial pubescente,
frequentemente opaca, às vezes brilhante, face

abaxial pubescente, nervuras primária e secundárias da face abaxial proeminentes. Flores em espigas terminais ou axilares, concentradas nos ápices dos ramos; raque ca. $1 \mathrm{~cm}$ compr.; brácteas triangulares 2$3 \mathrm{~mm}$ compr., 0,6-0,7 mm larg., pubescentes, ápice agudo, base truncada; bractéolas lineares 2,5-3,5 mm compr., pubescentes; cálice 5-partido, verde, sépalas unidas no quarto proximal, triangulares, ca. $8 \mathrm{~mm}$ compr., pubescentes; corola vermelha, 2,0-3,5 cm compr., lábios ca. $1,5 \mathrm{~cm}$ compr., o dorsal ereto, bidentado, o ventral trilobado, glabrescentes; estames inseridos pouco abaixo do ápice do tubo, curvados em direção ao lábio ventral, filete ca. $1,5 \mathrm{~cm}$ compr.; tecas da antera presas em alturas diferentes do conectivo, a teca superior com apêndice curto, ambas as tecas voltadas para o lábio ventral; disco nectarífero cobrindo o quarto proximal do ovário. Cápsulas ca. 2 $\mathrm{cm}$ compr., $4 \mathrm{~mm}$ larg., estipitadas, apiculadas, glabrescentes; retináculo ca. $2,5 \mathrm{~mm}$ compr. Sementes 3 mm diâm., lisas.

Material examinado: MINAS GERAIS: Lima Duarte, Parque Estadual de Ibitipoca, trilha para Gruta do Monjolinho, ao lado direito da trilha com cano, mata ciliar, 25.I.2010 (fl), Martinelli et al. 1 (SPF); no interior da mata nebular, 25.III.2001 (fl), Castro \& Heluey 188 (SPF); Serra de Ibitipoca, 12.V.1970 (fl, fr), Krieger 8618 (CESJ); Lago dos Espelhos, 22.II.1992 (fl), Eiterer \& Freitas 24 (CESJ); trilha para a Gruta do Pião, em meio a gramíneas, local ensolarado 23.II.1992 (fl), Eiterer \& Freitas 49 (CESJ); Serra de Ibitipoca, 12.V.1970 (fl), Krieger 8669 (CESJ); Gruta dos Viajantes, 23.II.1992 (fl), Eiterer \& Freitas 67 (CESJ); próximo à Gruta dos Coelhos, orla de mata, local sombrio, 19.V.1991 (fl, fr), Pires et al. s.n. (CESJ 24660); na descida pela vertente sul, próximo à divisa do parque, 29.VI.1991 (fl), Pires et al. s.n. (CESJ 25456).

Material adicional: MINAS GERAIS: Lima Duarte, arredores do Parque Estadual de Ibitipoca, trilha que sai da portaria do parque para o lado esquerdo, em mata ciliar, 9.II.2001 (fl), Forzza et al. 1818 (SPF); vilarejo de Mogol, sopé do pico Garcia, no campo rupestre, 23.II.2002 (fl), Valente 154 (SPF).

Justicia monticola ocorre em Minas Gerais e no Rio de Janeiro (Profice et al. 2014). Em Ibitipoca é amplamente distribuída pelas matas do parque. É uma espécie bem delimitada, mas apresenta variação na densidade de tricomas nos ramos e folhas, presentes nas populações de Ibitipoca. Tem hábito escandente mas, na ausência de um apoio, forma touceiras bem ramificadas. Espécimes coletados no entorno do parque apresentam lâminas mais curtas, com ápice agudo a obtuso e base obtusa a arredondada, com tricomas escassos e concentrados principalmente nas margens e nervuras.

\subsection{Justicia sebastianopolitana Profice,} Eugeniana 20: 2. 1993.

Arbustos ca. $70 \mathrm{~cm}$ alt. Ramos cilíndricos, glabros. Folhas membranáceas; pecíolo $0,7-1,1 \mathrm{~cm}$ compr.; lâmina 5,9-8,5 cm compr.; 1,2-2,2 cm larg., elíptica a ovada, ápice atenuado, base aguda a 


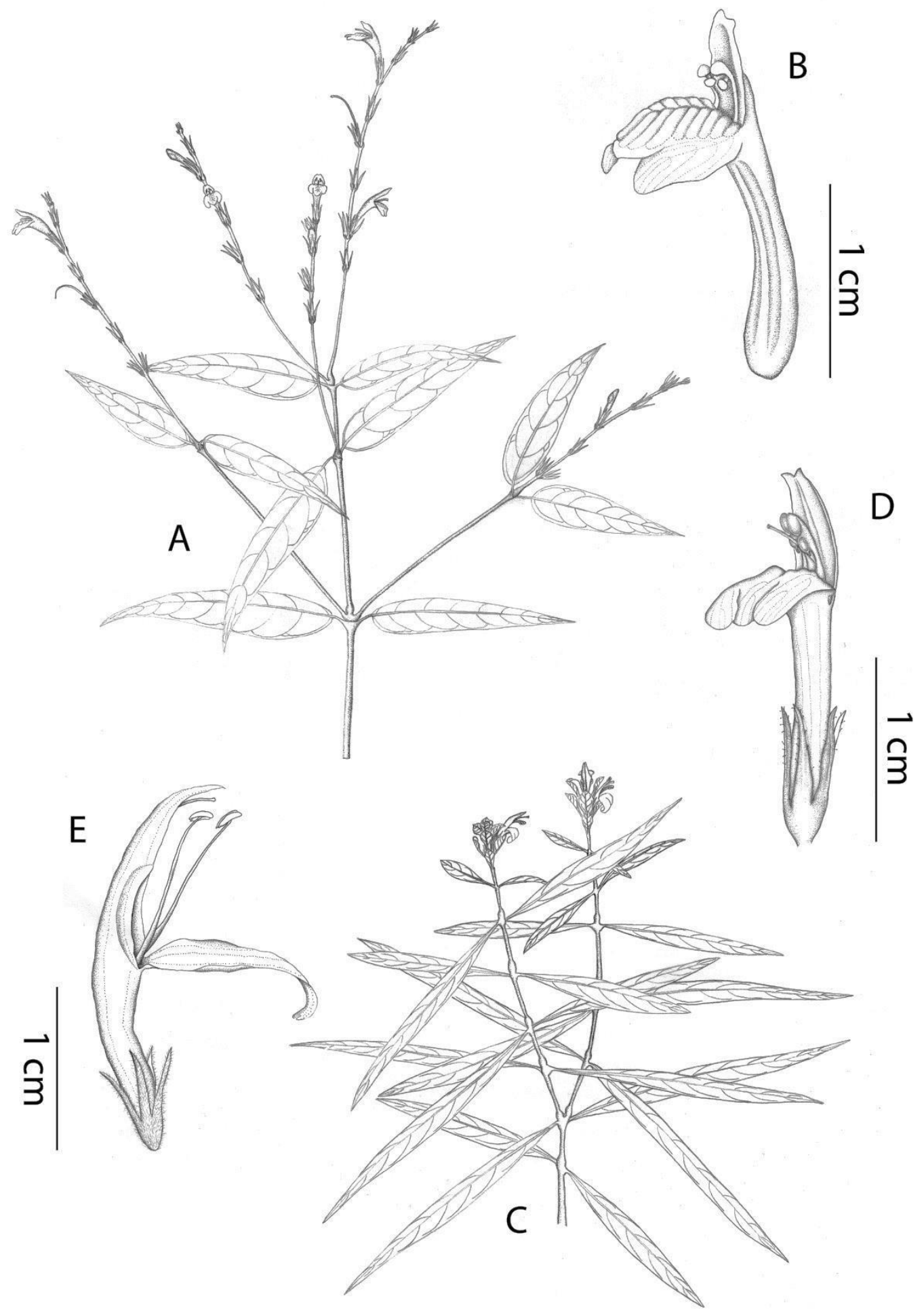

Fig. 1 - A-B - Justicia dasyclados. A. ramo florido; B. flor sem o cálice em vista látero-frontal (Martinelli 2). C-D. Justicia beyrichii. C. ramo florido; D. flor em vista látero-frontal (Martinelli 3). E. Justicia monticola, flor em vista lateral (Martinelli 1). 
atenuada, margem inteira ou levemente crenada, nervuras primária e secundárias proeminentes na face abaxial. Flores em espigas terminais ou axilares, simples ou compostas, raque 4,9 a $6,5 \mathrm{~cm}$ compr.; brácteas lanceoladas, 2,5-3,7 mm compr., glabrescentes; bractéolas lanceoladas, 3,3-4,2 mm compr., glabrescentes; cálice 5-partido, lacínias unidas no terço proximal, triangulares, $6-8 \mathrm{~mm}$ compr., $1 \mathrm{~mm}$ larg., glabrescentes; corola vermelha, ca. $2 \mathrm{~cm}$ compr., lábios $9 \mathrm{~mm}$ compr., o dorsal ereto, bidentado, o ventral trilobado, lobos $2 \mathrm{~mm}$ compr., o central mais largo, glabrescente; estames inseridos ca. $0,5 \mathrm{~cm}$ abaixo do ápice do tubo, tecas da antera paralelas, presas em alturas diferentes do conectivo, apendiculadas; disco nectarífero cobrindo o quarto proximal do ovário. Cápsulas ca. 1,3 cm compr., 0,3 cm larg., estipitadas, apiculadas, pubescentes; retináculo ca. $1,5 \mathrm{~mm}$ compr. Sementes ca. $2 \mathrm{~mm}$ diâm., rugulosas.

Material examinado: MINAS GERAIS: Lima Duarte, Conceição de Ibitipoca, Parque Estadual de Ibitipoca, na vertente sul, no limite do parque, na mata ciliar, 29.VI.1991 (fl, fr), Salimena-Pires et al. s.n. (CESJ 25454, SPF); Gruta da Cruz, 18.VII.1994 (fl), Ladeira s.n. (CESJ 27493); trilha para os Três Arcos, mata, 27.VII.1991 (fl), Eiterer et al. s.n. (CESJ 24872).

Justicia sebastianopolitana ocorre na região Sudeste do Brasil, exceto no Espírito Santo (Profice et al. 2014). No Parque do Ibitipoca pode ser encontrada em regiões de mata próximas a grutas.

\section{Agradecimentos}

Os autores agradecem ao banco SANTANDER pela bolsa de Iniciação Científica de Isabel Martinelli, desenvolvida na Universidade de São Paulo (USP) e ao Conselho Nacional de Desenvolvimento Científico e Tecnológico (CNPq) pela Bolsa de Produtividade de Renato Mello-Silva. Agradecem também ao Instituto Estadual de Florestas de Minas Gerais (IEF) pelo apoio aos trabalhos em lbitipoca e a dois assessores anônimos pelas contribuições valiosas.

\section{Referências}

ANDRADE, P.M. \& SOUSA, H.C. 1995. Contribuição ao conhecimento da vegetação do Parque Estadual de Ibitipoca, Lima Duarte, Minas Gerais. Rev. Árvore 19(2): 249-261.

BARROSO, G.M. 1978. Sistemática de angiospermas do Brasil. EDUSP. São Paulo.

BARROSO, G.M., PEIXOTO, A.L., COSTA, C.G., ICHASO, C.L.F., GUIMARÃES, E.F. \& LIMA, H.C. 1991. Sistemática das angiospermas do Brasil. Vol.3. Imprensa Universitária. Viçosa.
BELL, A.D. 1991. Plant form: an illustrated guide to flowering plant morphology. Oxford University Press. Oxford.

BORGES, R.A.X. \& FORZZA, R.C. 2008. A tribo Astereae (Asteraceae) no Parque Estadual do Ibitipoca, Minas Gerais, Brasil. Bol. Bot. Univ. São Paulo 26: 131-154.

BRAZ, D.M., CARVALHO-OKANO, R.M. \& KAMEYAMA, C. 2002. Acanthaceae da Reserva Florestal Mata do Paraíso, Viçosa, Minas Gerais. Rev. Bras. Bot. 25: 495-504.

BURKILL, H.M. 1985. The useful plants of West Africa. Royal Botanic Gardens. Kew.

CARVALHO, L.M.T., FONTES, M.A. \& OLIVEIRA FILHO, A. 2000. Tree species distribution in canopy gaps and mature forest in an area of cloud forest of the Ibitipoca Range, south-eastern Brazil. Plant Ecol. 149: 9-22.

DRUMMOND, G.M., MARTINS, C.S., MACHADO, A.B.M., SEBAIO, F.A. \& ANTONINI, Y. (orgs.). 2005. Biodiversidade em Minas Gerais: um atlas para sua conservação. Fundação Biodiversitas. Belo Horizonte.

EZCURRA, C. 1993. Systematics of Ruellia (Acanthaceae) in Southern South America. Ann. Missouri Bot. Gard. 80(4): 787-845.

EZCURRA, C. 2002. El género Justicia (Acanthaceae) en Sudamérica Austral. Ann. Missouri Bot. Gard. 89: 225-280.

FERREIRA, M.B. \& MAGALHÃES, G.M. 1977. Contribuição para o conhecimento da vegetação da Serra do Espinhaço em Minas Gerais (Serras de Grão Mogol e da lbitipoca). Anais do XXVI Congr. Nac. Bot. Academia Brasileira de Ciências. Rio de Janeiro. Pp. 189-202.

FORZZA, R.C., BARROS, F. \& SALIMENA-PIRES, F.R. 1994. Orchidaceae do Parque Estadual de Ibitipoca, Minas Gerais (checklist). Principia 1: 125136.

FORZZA, R.C., MENINI NETO, L., SALIMENA, F.R. \& ZAPPI, D.C. (orgs.). 2013. Flora do Parque Estadual do Ibitipoca e seu entorno. Editora UFJF. Juiz de Fora.

HICKEY, LJ. 1973. Classification of the architecture of dicotyledonous leaves. Am. J. Bot. 60(1): 17-33.

KAMEYAMA, C. 1995. Flora da Serra do Cipó, Minas Gerais: Acanthaceae. Bol. Bot. Univ. São Paulo 14: 181-206.

KAMEYAMA, C. 2003. Flora de Grão-Mogol, Minas Gerais: Acanthaceae. Bol. Bot. Univ. São Paulo 21: 51-53.

MABBERLEY, D.J. 2008. Mabberley's plant-book: a portable dictionary of plants, their classification and uses. Cambridge University Press. Cambridge. 
MEDEIROS, E.S.S. \& GUIMARÃES, E.F. 2007. Piperaceae do Parque Estadual de Ibitipoca, Minas Gerais, Brasil. Bol. Bot. Univ. São Paulo 25: 227252.

MENINI NETO, L. 2007. A subtribo Pleurothallidinae Lindl. (Orchidaceae) no Parque Estadual de Ibitipoca, Minas Gerais. Bol. Bot. Univ. São Paulo 25(2): 253-278.

MENINI NETO, L., ALVES, R.J.V., BARROS, F. \& FORZZA, R.C. 2007. Orchidaceae do Parque Estadual de Ibitipoca, MG, Brasil. Acta Bot. Bras. 21(3): 687-696.

MILWARD-DE-AZEVEDO, M.A. 2007. Passifloraceae do Parque Estadual de Ibitipoca, Minas Gerais. Bol. Bot. Univ. São Paulo 25(1): 71-79.

MONGUILHOTT, L. \& MELLO-SILVA, R. 2009. Apocynaceae do Parque Estadual de Ibitipoca, Minas Gerais, Brasil. Bol. Bot. Univ. São Paulo 26: 93-130.

NEES, C.G. 1847. Acanthaceae. In Martius, C.F.P. (ed.) Flora brasiliensis. Vol. 9. Fridrich Fleischer. Leipzig, p. 1-164.

PROFICE, S.R. 1988. Mendoncia Vell. ex Vand. (Acanthaceae). Espécies ocorrentes no Brasil. Arq. Jard. Bot. Rio de Janeiro 29: 201-279.

PROFICE, S.R., KAMEYAMA, C., CÔRTES, A.L.A., BRAZ, D.M., INDRIUNAS, A., VILAR, T., PESSOA, C. EZCURRA, C. \& WASSHAUSEN, D. 2014. Acanthaceae in Lista de Espécies da Flora do Brasil. Jardim Botânico do Rio de Janeiro. (http://reflora.jbrj.gov.br/jabot/floradobrasil/FB4167)
RODELA, L.G. 1998. Cerrados de altitude e campos rupestres do Parque Estadual de Ibitipoca, sudeste de Minas Gerais: distribuição e florística por subfisionomias da vegetação. Rev. Depto. Geo. USP 12: 163-189.

RODELA, L.G. \& TARIFA, J.R. 2002. O clima na Serra do Ibitipoca, sudeste de Minas Gerais. Geousp Revista Espaço e Tempo 11: 101-113.

SALIMENA-PIRES, F.R. 1997. Aspectos fisionômicos e vegetacionais do Parque Estadual de Ibitipoca, Minas Gerais, Brasil. Pp. 51-60. In G.C. Rocha (coord), Anais do $1^{\circ}$ Seminário de Pesquisa sobre - Parque Estadual de Ibitipoca. Núcleo de Pesquisa em Zoneamento Ambiental da UFJF. Juiz de Fora.

SCOTLAND, R.W. \& VOLLESEN, K. 2000. Classification of Acanthaceae. Kew Bull. 55: 513589.

THEOBALD, W.L., KRAHULIK, J.L. \& ROLLINS, R.C. 1979. Trichome description and classification. $p$. 40-53. In C.R. Metcalfe \& L. Chalk (eds.) Anatomy of the Dicotyledons. Systematic anatomy of the leaf and stem, with a brief history of the subject. Vol. 2. Claredon Press. Oxford.

THIERS, B. 2010 [continuously updated]. Index herbariorum: A global directory of public herbaria and associated staff. New York Botanical Garden's Virtual Herbarium. http://sweetgum.nybg.org/ih/ (Jun. 2014).

WASSHAUSEN, D.C. \& WOOD, J.R.I. 2004. Acanthaceae of Bolivia. Contr. U.S. Natl. Herb. 49: $1-152$. 